\title{
Review
}

\section{Health-promoting effects of green tea}

\author{
By Yasuo SuZukI, ${ }^{* 1}$ Noriyuki MrYOSHI ${ }^{* 2}$ and Mamoru ISEMurA*2,† \\ (Communicated by Takao SEKIYA, M.J.A.)
}

\begin{abstract}
Green tea is manufactured from the leaves of the plant Camellia sinensis Theaceae and has been regarded to possess anti-cancer, anti-obesity, anti-atherosclerotic, antidiabetic, anti-bacterial, and anti-viral effects. Many of the beneficial effects of green tea are related to the activities of (-)-epigallocatechin gallate (EGCG), a major component of green tea catechins. For about 20 years, we have engaged in studies to reveal the biological activities and action mechanisms of green tea and EGCG. This review summarizes several lines of evidence to indicate the health-promoting properties of green tea mainly based on our own experimental findings.
\end{abstract}

Keywords: green tea, catechin, health promotion, molecular mechanism, gene expression

\section{Introduction}

Green tea (Camellia sinensis Theaceae) was discovered in China in $3000 \mathrm{BC}$ or earlier and has been known to have various medical effects. ${ }^{1)}$ It was brought to Japan from China by Buddhist priests over a thousand years ago. In 1211, a Japanese Zen priest, Yeisai, published the book "Kitcha-Yojoki" (Tea and Health Promotion) in which the methodology of harvesting tea leaves, production processes for tea, and pharmacological effects were described. Nowadays, scientific evidence indicates that green tea is indeed beneficial to health and many of the components of tea have specific health-promoting effects. $^{1-12)}$ For example, tea catechins (Fig. 1), especially (-)-epigallocatechin gallate (EGCG), are considered to be associated with the anti-cancer, anti-obesity, anti-atherosclerotic, anti-diabetic, antibacterial, anti-viral, and anti-dental caries effects of tea. Caffeine stimulates wakefulness, decreases the

\footnotetext{
*1 Faculty of Human Life Sciences, Nagoya Keizai University, Inuyama, Japan.

*2 Graduate School of Nutritional and Environmental Sciences and Global COE Program, University of Shizuoka, Shizuoka, Japan.

$\dagger$ Correspondence should be addressed: M. Isemura, Graduate School of Nutritional and Environmental Sciences, University of Shizuoka, 52-1 Shizuoka, Suruga-ku, Shizuoka 422-8526, Japan (e-mail: isemura@u-shizuoka-ken.ac.jp).

Abbreviations: EGCG: (-)-epigallocatechin gallate; G6Pase: glucose-6-phosphatase; HNF: hepatocyte nuclear factor; MMP: matrix metalloproteinase; NF- $\kappa$ B: nuclear factor kappa B; PEPCK: phosphoenolpyruvate carboxykinase; TNF- $\alpha$ : tumor necrosis factor- $\alpha$.
}

sensation of fatigue, and has a diuretic effect. Theanine and $\gamma$-aminobutyric acid act to lower blood pressure and regulate brain and nerve functions. Vitamin $\mathrm{C}$ is an anti-scorbutic, prevents cataracts, and strengthens the immune system.

For about 20 years, we have examined the biological activities of green tea and its major polyphenolic compound catechins. In the present article, we review the health-promoting beneficial effects of green tea mainly based on our own published results.

\section{Anti-metastatic and anti-cancer activities}

Much attention has been paid to the anti-cancer activity of green tea and tea catechins with animal and cell experiments. ${ }^{1-5), 7)-12)}$ In 1993, we reported that EGCG, the major catechins in green tea, inhibited the adhesion of cancer cells to endothelial cell layers. ${ }^{13)}$ We also found that EGCG prevented cancer cells from attaching to fibronectin ${ }^{14)}$ and laminin, ${ }^{15)}$ two components of the endothelial basement membrane. ${ }^{16), 17)}$ These findings suggested green tea to have an anti-metastatic effect (Fig. 2). Indeed, we found that a green tea infusion was effective at preventing cancer cell metastasis using in vivo and in vitro models. ${ }^{18)}$ The peroral administration of green tea infusion reduced the number of lung colonies of mouse Lewis lung carcinoma cells in a spontaneous metastasis system. The experiments with artificially reconstituted basement membrane indicated that the green tea infusion and its constituent catechins prevented cancer cells from 
<smiles>COc1ccc([C@@H]2Oc3cc(O)cc(O)c3C[C@H](O)[C@@H]2C)cc1O</smiles>

(+)-catechin<smiles>Oc1cc(O)c2c(c1)O[C@H](c1ccc(O)c(O)c1)[C@H](O)C2</smiles>

(-)-epicatechin<smiles>Oc1cc(O)c2c(c1)O[C@H](c1cc(O)c(O)c(O)c1)[C@H](O)C2</smiles>

(-)-epigallocatechin<smiles>O=C(O[C@H]1Cc2c(O)cc(O)cc2O[C@H]1c1ccc(O)c(O)c1)c1cc(O)c(O)c(O)c1</smiles>

\section{(-)-epicatechin gallate}<smiles>O=C(O[C@H]1Cc2c(O)cc(O)cc2O[C@H]1c1cc(O)c(O)c(O)c1)c1cc(O)c(O)c(O)c1</smiles>

\section{(-)-epigallocatechin gallate}

Fig. 1. Chemical structure of catechins. (-)-Epicatechin, (-)-epigallocatechin, (-)-epicatechin gallate and EGCG are major green tea catechins.

the penetration through the basement membrane. These findings were consistent with those of Taniguchi et al. who reported that EGCG inhibited lung metastasis in mouse B16 melanoma cell lines. ${ }^{19)}$

Since the metastatic process includes the degradation of the basement membrane containing type IV collagen (Fig. 2), green tea catechins may inhibit collagenases or matrix metalloproteinases (MMPs). We observed that EGCG was a strong inhibitor for MMP-2 and MMP-9 derived from cancer cells ${ }^{20), 21)}$ and MMP-3 (stromelysin). ${ }^{22)}$ Since EGCG binds to some proteins including fibronectin in blood plasma, ${ }^{23), 24)}$ it could conceivably bind to MMPs directly to exhibit inhibitory activity. This was proven by an experiment using affinity chromatography. ${ }^{20)}$ In later experiments, we found that EGCG inhibited the gene expression of MMPs as well. ${ }^{25), 26)}$

Apoptosis is a programmed cell death and inducing apoptosis in tumor cells is a primary mechanism of action of certain anti-tumor drugs. ${ }^{27), 28)}$ The anti-tumor mechanism of green tea appears to include the induction of apoptosis by EGCG through production of $\mathrm{H}_{2} \mathrm{O}_{2},{ }^{29)}$ inhibition of cell-cycle progression, ${ }^{30)}$ inhibition of nuclear factor kappa B $(\mathrm{NF}-\kappa \mathrm{B}),{ }^{3), 31)}$ activation of the mitogen-activated protein kinase cascade ${ }^{32}$ and binding to a $67 \mathrm{kDa}$ laminin receptor. ${ }^{8)}$ In 1996, the first finding that catechins induce apoptosis was made by Hibasami et al. ${ }^{33)}$ in human leukemia Molt $4 \mathrm{~B}$ cells. We observed that EGCG induced apoptosis in human lymphoma U937 cells as evidenced by the events including formation of apoptotic bodies and degradation of DNA into nucleosomal units. ${ }^{34)}$ There is a structure-function relationship in the apoptosis induction by catechins. The $5^{\prime}$ (or $3^{\prime}$ )-hydroxyl group in the B-ring plays an important role and a pyrogalloltype structure in a molecule is the minimum requirement for apoptosis induction ${ }^{35)}$ (see Fig. 1).

Consistent with the findings made in vitro, EGCG reduced numbers of colonic aberrant cryptic foci with an increase in apoptosis and enhanced the actions of the drug sulindac in an azoxymethaneinduced model of colonic carcinogenesis. ${ }^{36)}$ Gupta et al. ${ }^{37)}$ showed that in autochthonous transgenic adenocarcinomas of the mouse prostate, oral infusion of green tea catechins inhibited prostate cancer development accompanied by enhanced apoptosis.

In addition, we have proposed that the involvement of the direct binding of EGCG to Fas, one of the death receptor proteins on the surface membrane 


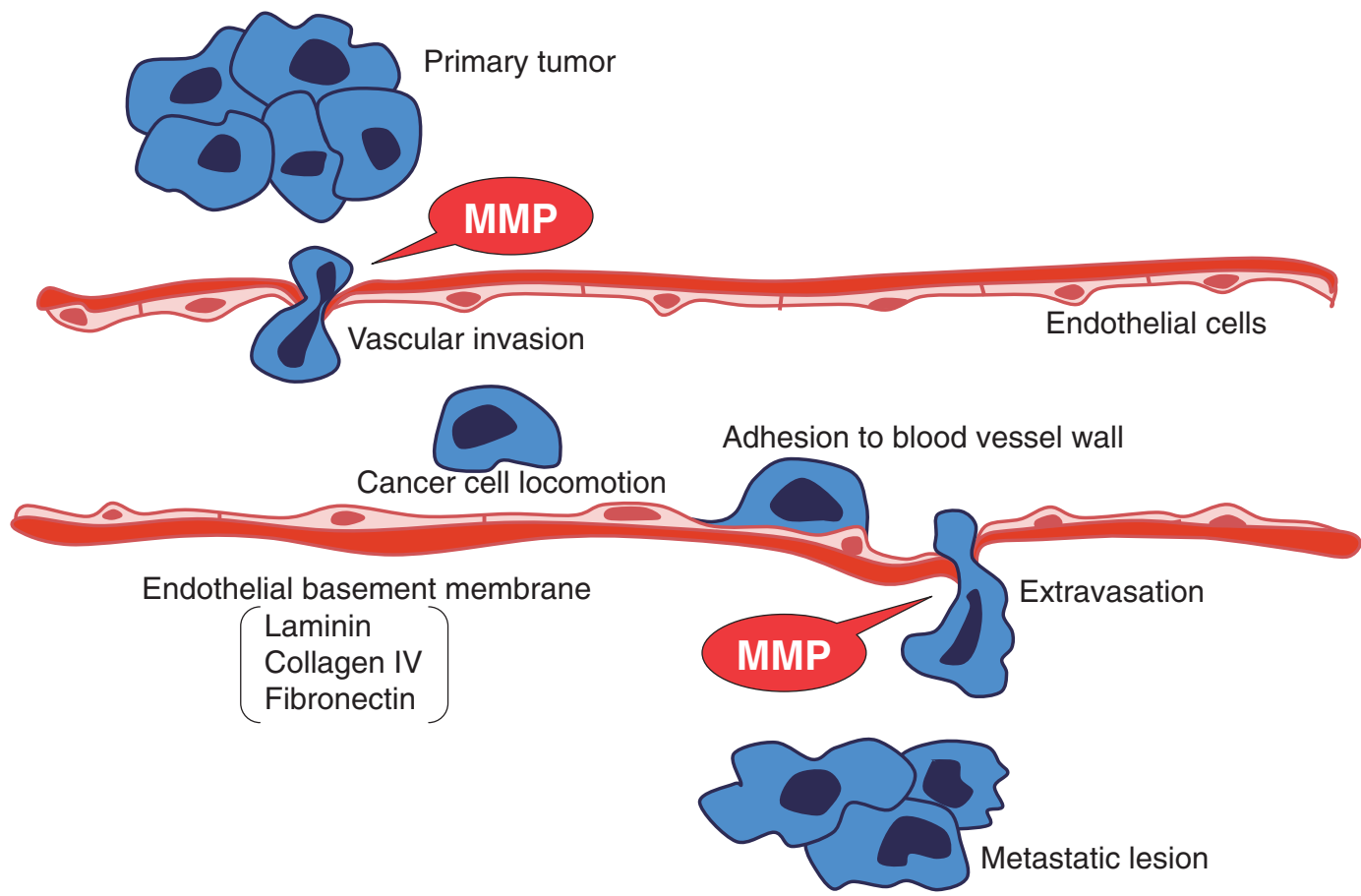

Fig. 2. A model depicting blood-borne metastasis of tumor cells. Cancer metastatic cells invade into the blood flow by degrading the endothelial basement membrane. After adhesion to the blood vessel wall, they extravasate by local degradation to form metastatic tumor colony. Tumor-associated proteinases such as MMPs have critical roles in degradation of the basement membrane containing laminin, collagen IV and fibronectin.

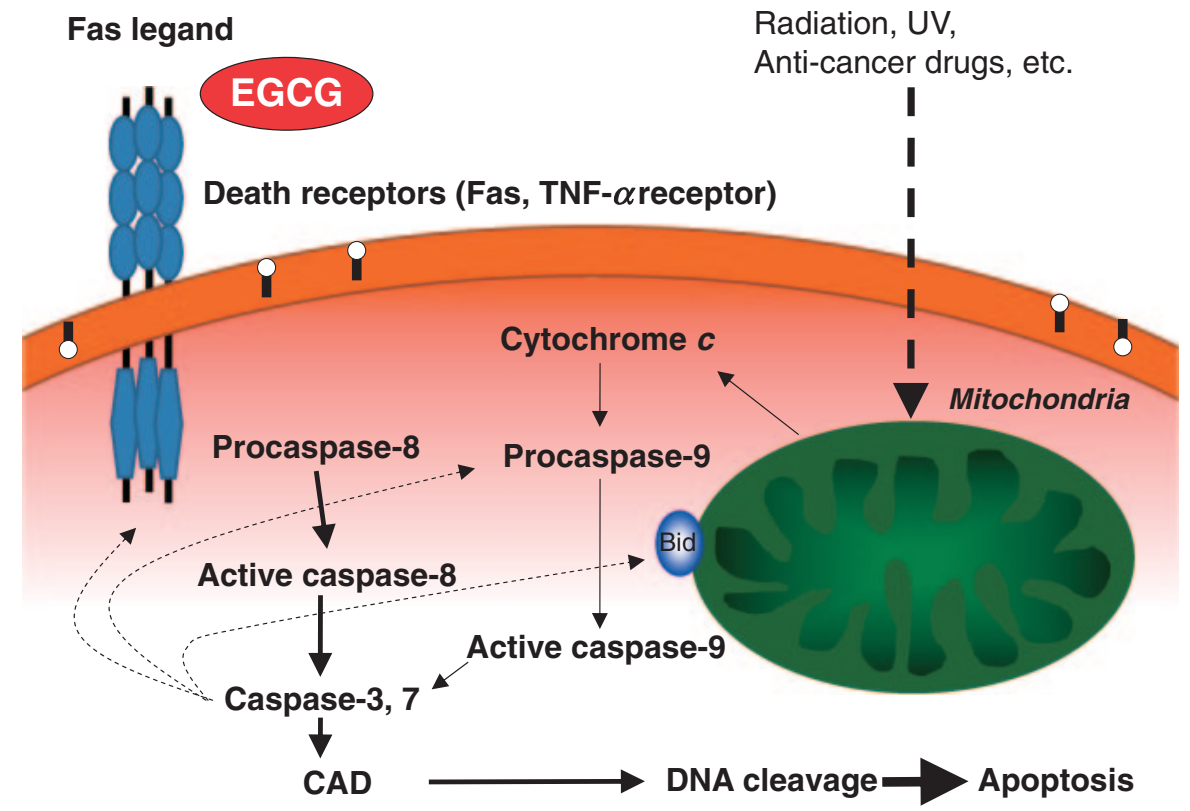

Fig. 3. A model depicting apoptosis through death receptor Fas and the action mechanism of EGCG. CAD, caspase-activated deoxyribonuclease. Binding of EGCG to Fas triggers apoptosis by activating the death receptor signaling. 
of cells ${ }^{38)}$ to initiate signal transduction for apoptosis (Fig. 3). The Fas-Fas ligand system is one of the major pathways operating in the apoptotic cascade. The EGCG treatment of human monocytic leukemia U937 cells resulted in elevation of caspase 8 activity and fragmentation of caspase 8 . The DNA ladder formation caused by the EGCG treatment was inhibited by the caspase 8 inhibitor. These findings suggested the involvement of the Fas-mediated cascade in the EGCG-induced apoptosis in U937 cells. Affinity chromatography revealed the binding between EGCG and Fas. Thus, the results suggest that EGCG-binding to cell surface Fas triggers the Fas-mediated apoptosis in U937 cells. This study was the first to demonstrate that EGCG binds to cell surface protein to exert its biological action and confirmed the usefulness of affinity chromatography with EGCG immobilized on Sepharose 4B to find out the EGCG-binding proteins as used to identify those in serum. ${ }^{23)}$ The method was successfully used in several later studies to identify proteins involved in EGCG-mediated growth inhibition and apoptosis of cancer cells. ${ }^{39)-44)}$ Recently, an alternate method using agarose-bound $m$-aminophenylsulfonyl boronic acid has been developed to search for EGCG-binding proteins. ${ }^{45)}$ Its use in combination with reductionoxidation cycling staining made it possible to visualize EGCG-binding proteins. These methods ${ }^{23), 45)}$ have provided evidence that EGCG binds to several intracellular proteins such as vimentin and the ATPdependent RNA helicase DDX5, indicating that EGCG can enter into the cell.

It has been well documented that cancer cells are more susceptible to apoptosis induced by EGCG than normal counterparts. ${ }^{46), 47)}$ There is a possibility that normal cells express larger amounts of several EGCG-binding, Fas-like decoy proteins on the cell surface than cancer cells, leading to a diminution in the concentration of EGCG available to bind Fas, resulting in resistance to apoptosis. ${ }^{48}$ We also showed that differentiated HL-60 cells were resistant to EGCG-induced apoptosis as compared with undifferentiated cells, suggesting that EGCG induces apoptosis selectively in cancer cells. ${ }^{49)}$ However, the change in the expression of cell surface Fas-like decoy proteins after differentiation has yet to be examined.

The EGCG-induced change in the redox state of cancer cells ${ }^{32)}$ may also be involved in the mechanism. It is important to point out that green tea contains a high molecular weight fraction which induces apoptosis in cancer cells by a mechanism including cell cycle arrest. ${ }^{50), 51)}$ Thus, our results support the view that drinking green tea is useful to prevent cancer.

Epidemiological and intervention studies are important to reveal the anti-cancer effects of green tea and catechins. The first impressive result was reported in 1989 by Oguni et al. ${ }^{52)}$ who described that the rate of death from stomach cancer in males of the town of Nakakawane was about one fifth of the average for Japanese males overall and that this low rate might be related to the consumption of green tea. Later, it was reported that tea consumption did not correlate to the risk of stomach cancer. ${ }^{53), 54)}$ However, other studies revealed an inverse association between green tea consumption and distal gastric cancer among Japanese women ${ }^{55)}$ and a reduced risk of stomach cancer with intake of green tea. ${ }^{56)}$ The discrepancy in results may arise from factors such as differences in the type of tea consumed, in cancer etiology, in confounding lifestyle, and in genetic factors. Future epidemiological studies should include a measurement of urinary tea polyphenols, including epigallocatechin and epicatechin, and their respective metabolites to provide more reliable data on the relationship between tea consumption and cancer risk as exemplified by the study of Sun et al. ${ }^{2)}$

More convincing data for the effects of green tea were presented by Bettuzzi et al. ${ }^{57)}$ who conducted a clinical trial to assess the safety and efficacy of green tea catechins for the chemoprevention of prostate cancer in individuals with high-grade prostate intraepithelial neoplasias. After 1 year of daily treatment consisting of three capsules containing $200 \mathrm{mg}$ of catechin, only one tumor was diagnosed among the 30 catechin-treated men, whereas 9 cancers were found among the 30 placebo-treated men. Recently, a $15 \%$ ointment of Polyphenon ${ }^{\circledR}$ E, a defined extract of green tea catechins, proved to be efficacious and safe in the treatment of external genital warts which are non-malignant squamous cell tumors caused by infections of human papilloma viruses. ${ }^{58), 59)}$ These findings are encouraging further clinical studies on chemopreventive effects of green tea catechins.

\section{Hepatoprotective effects}

Galactosamine is known to induce hepatic injury in rats that is similar in pathophysiology to viral hepatitis and drug-induced hepatitis in humans. ${ }^{60)}$ Green tea has been shown to suppress galactosamineinduced liver injury in rats ${ }^{61), 62}$ and one of the active components was identified as glycosidic flavonoids. ${ }^{62}$ ) In our study, intraperitoneal injection of galactos- 


\section{Galactosamine, ischemia-reperfusion, encephalitis-inducing agents}

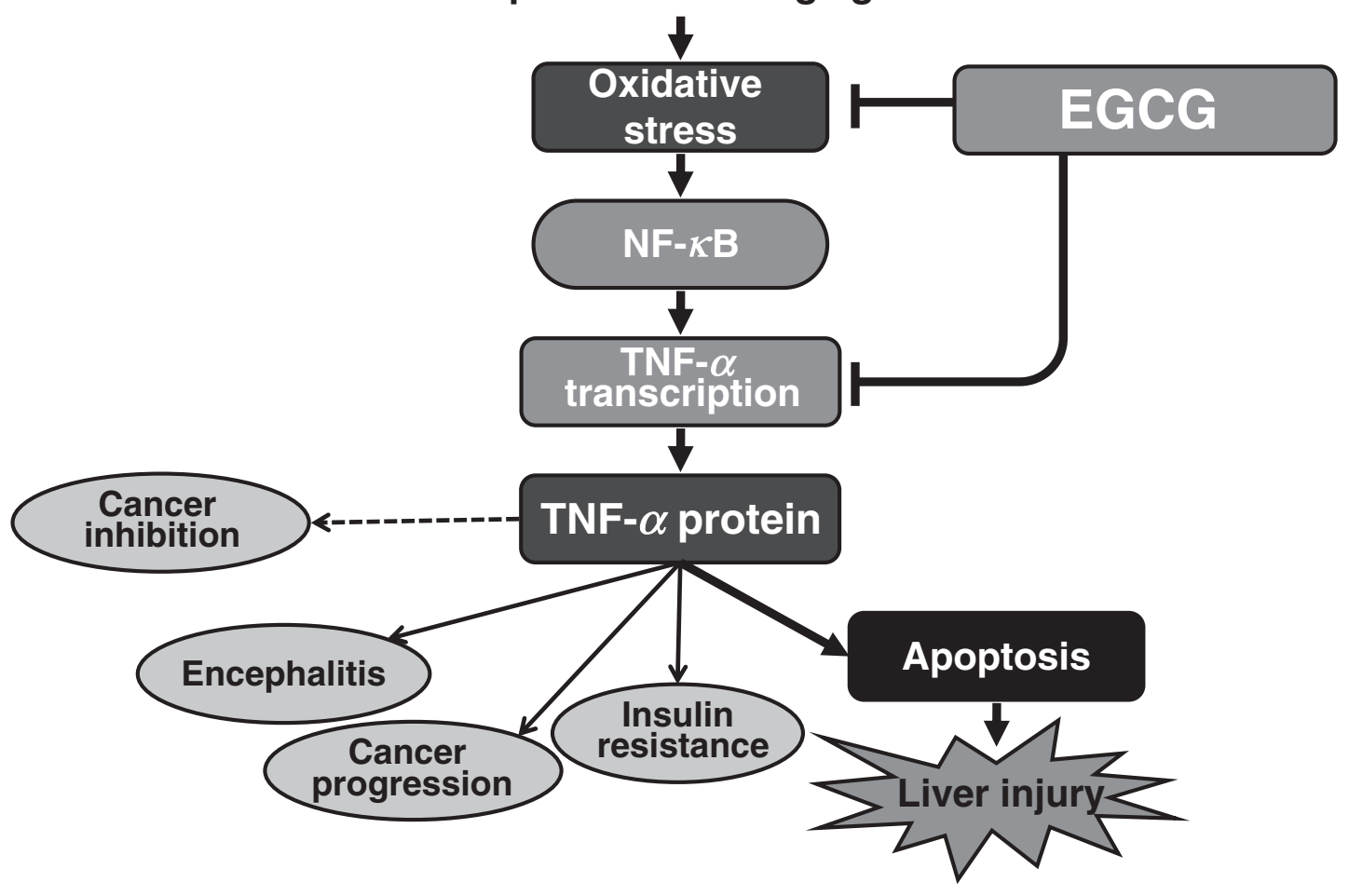

Fig. 4. The action mechanism of EGCG through inhibition of gene and protein expression of TNF- $\alpha$. Liver injury induced with galactosamine or ischemia-reperfusion and encephalitis induced with proteolipid protein 139-151 are prevented by EGCG by reducing oxidative stress and/or decreasing TNF- $\alpha$ transcription. Anti-cancer effects of EGCG may include its suppression of TNF- $\alpha$ gene expression. EGCG may also have beneficial effects on TNF- $\alpha$-associated diseases such as diabetes.

amine $(500 \mathrm{mg} / \mathrm{kg})$ induced liver injury with necrosis in rats and the oral administration of green tea rich in catechins inhibited the galactosamine's action. Green tea restored levels of several biomarkers in galactosamine-treated rats to near control values. ${ }^{63)}$ These biomarkers included serum transaminase activities, serum concentrations of tumor necrosis factor- $\alpha$ (TNF- $\alpha$ ) and interleukin 1- $\beta$, and the hepatic mRNA expression of these inflammatory cytokines. The serum concentration in green tea-treated rats was about $55 \%$ of rats untreated after galactosamine injection. Since apoptosis of liver cells is involved in galactosamine-induced liver injury ${ }^{64)}$ and TNF- $\alpha$ induces apoptosis, ${ }^{65)}$ modulation of TNF- $\alpha$ appears to be a key action of EGCG (Fig. 4).

Hepatic ischemia-reperfusion activates Kupffer cells and initiates severe oxidative stress with enhanced production of reactive oxygen species (ROS) and TNF- $\alpha$. Giakoustidis et al. ${ }^{66)}$ reported the hepatoprotective effect of EGCG in rats by inhibiting apoptosis through attenuation of the expression of NF- $\kappa \mathrm{B}$, c-Jun, and caspase- 3 in an experimental model of severe hepatic ischemiareperfusion. Similarly, Okabe et al. ${ }^{65)}$ demonstrated that green tea catechins induced growth inhibition and apoptosis by reducing TNF- $\alpha$ gene expression and TNF- $\alpha$ release, using the human stomach cancer cell line KATO III (Fig. 4). The EGCG's action to suppress TNF- $\alpha$ expression may also have beneficial effect on diabetes, since TNF- $\alpha$ is involved in developing diabetes. ${ }^{67)}$

We also found that catechin-rich green tea prevented liver fibrosis after hepatic injury induced by galactosamine through the down-regulation of the gene expression of collagens. ${ }^{68)}$ Thus, green tea appears to have hepatoprotective effects. From a clinical point of view, the application of catechins to therapy for hepatitis $\mathrm{C}$ appears to be promising. ${ }^{69)}$ However, it should be noted that hepatotoxicity associated with supplements containing green tea has been reported, ${ }^{70}$ ) although animal experiments showed no evidence of characteristic hepatotoxicity 
in rats treated with very large amounts of different green tea extracts. ${ }^{71)}$

\section{Anti-diabetic effects}

Research into the relationship between green tea and obesity-related insulin resistance syndrome has shown that green tea enhances insulin activity in vitro, ${ }^{72)}$ enhances insulin sensitivity in human subjects ${ }^{73)}$ and rats, ${ }^{74)}$ and reduces hypertriacylglycerolaemia in mice. ${ }^{75)}$ One of the hallmarks of diabetes is the inability of insulin to inhibit hepatic glucose production. ${ }^{76)}$ Increased gluconeogenesis is a main source of increased hepatic glucose production and the ability of insulin to regulate transcription of the rate-controlling gluconeogenic enzymes, phosphoenolpyruvate carboxykinase (PEPCK) and glucose-6-phosphatase (G6Pase), may contribute to this problem.

In experiments using rat hepatoma H4IIE cells, EGCG was shown to mimic the cellular effects of insulin including the reductive effect on the gene expression of these gluconeogenic enzymes. ${ }^{76)}$ It is very important to know whether or not such finding in vitro is relevant to the in vivo situation. We demonstrated that administration of EGCG caused a reduction in the level of mRNAs for these gluconeogenic enzymes in the mouse liver. ${ }^{77}$ ) Green tea was also shown to down-regulate the gene expression of these gluconeogenic enzymes. ${ }^{77)}$ Wolfram et al. ${ }^{78)}$ reported a pronounced decrease of glucose levels in food-deprived $\mathrm{db} / \mathrm{db}$ mice treated with EGCG. The results for gene expression in liver and adipose tissues of $\mathrm{db} / \mathrm{db}$ mice supplemented with EGCG for 7 weeks showed that PEPCK expression was significantly down-regulated in the adipose tissue, although the down-regulation was not significant statistically in the liver.

Our recent findings indicate that EGCG downregulates the gene expression of these gluconeogenic enzymes by reducing the gene and protein expression of hepatocyte nuclear factor (HNF) $4 \alpha$, a key transcription factor for PEPCK and G6Pase ${ }^{79)}$ (Fig. 5). Insulin is known to reduce the protein expression of $\mathrm{HNF} 4 \alpha^{80)}$ and, therefore, EGCG has an insulinmimetic property in this sense. EGCG also reduced the intestinal expression of these gluconeogenic enzymes in association with the down-regulation of $\mathrm{HNF} 4 \alpha$ and $\mathrm{HNF} 1 \alpha{ }^{81)}$

In a more recent study, we showed that an EGCG-free fraction derived from a green tea infusion had effects similar to those of EGCG. ${ }^{82)}$ The hot water infusion of green tea leaves was separated into an ethanol-soluble fraction and an EGCG-free watersoluble fraction (GT-W). GT-W reduced the gene expression of G6Pase and PEPCK in H4IIE cells and caused a decrease in expression of the transcription factor HNF4 $\alpha$. Reduced levels of PEPCK and HNF $4 \alpha$ proteins were demonstrated in the cells treated with GT-W. Administration of GT-W to mice for 4 weeks reduced the hepatic expression of G6Pase, PEPCK, and HNF4 $\alpha$. However, the action mechanism appears different because EGCG's action was attenuated by a reducing agent, $N$-acetylcysteine, ${ }^{82)}$ suggesting a change in the redox state of the cells to be involved, whereas the activity of GT-W was not affected by this agent. ${ }^{83)}$ These results suggest that green tea consumption and dietary supplementation with EGCG could potentially contribute to nutritional strategies for the prevention and treatment of type 2 diabetes mellitus through their effects to reduce the fasting blood glucose concentration by down-regulating the hepatic gene expression of gluconeogenic enzymes. ${ }^{76)}, 78$ )

A recent large-scale retrospective cohort study revealed that consumption of green tea, coffee, and total caffeine was associated with a reduced risk for type 2 diabetes mellitus. ${ }^{84)}$ Panagiotakos et al. ${ }^{85)}$ reported that long-term tea intake was associated with reduced levels of fasting blood glucose and a lower prevalence of diabetes, in a cohort of elderly people living on Mediterranean islands.

\section{Anti-obesity and anti-atherosclerotic effects}

In the book "Yojokun" published in the Edo period, Ekiken Kaibara described that according to the ancient Chinese medical doctor, long-term drinking of green tea would result in a lean body by removing body fat. Evidence has accumulated to show that the ingestion of green tea and tea catechins leads to a reduction in body fat as described in recent reviews. ${ }^{86)-88)}$ The stimulation of hepatic lipid metabolism might be a factor responsible for the antiobesity effects of tea catechins. Tea catechins are suggested to inhibit cell growth by suppressing lipogenesis in human MCF-7 breast cancer cells through down-regulation of fatty acid synthase gene expression in the nucleus and stimulation of cell energy expenditure in the mitochondria. ${ }^{89)}$ The experimental data indicated that the suppression of fatty acid synthase gene expression by tea polyphenols may lead to down-regulation of EGFR/PI3K/ Akt/Sp-1 signal transduction.

In addition to EGCG's effects described above, we observed that oral administration of an EGCG- 

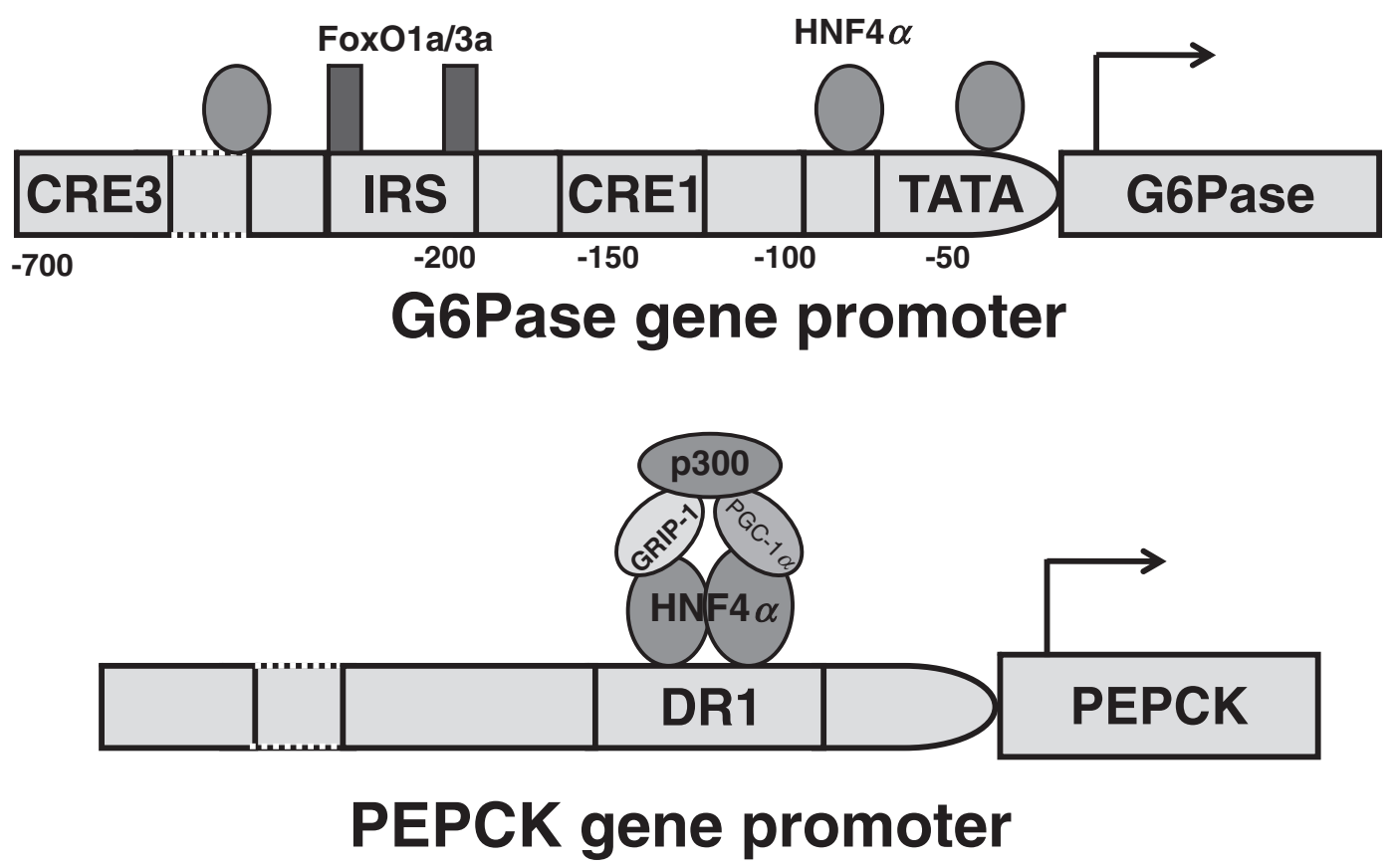

Fig. 5. HNF4 $\alpha$-mediated gene expression of gluconeogenic enzymes. The G6Pase gene promoter contains three HNF4 $\alpha$ binding sites and the PEPCK gene promoter has the binding site of its dimer to which several co-factors bind. CRE, cyclic AMP responsive element; DR, direct repeat spaced by one nucleotide; FoxO, forkhead/winged helix box gene group O; GRIP, glucocorticoid receptorinteracting protein; IRS, insulin response sequence; PGC, peroxisome proliferator-activated receptor- $\gamma$ coactivator.

free green tea fraction reduced the hepatic gene expression of PEPCK and G6Pase. ${ }^{83)}$ This fraction also reduced the hepatic gene expression of lipogenic enzymes such as fatty acid synthase, 4-hydroxymethylglutaryl CoA reductase, acetyl CoA carboxylase $\alpha$, and ATP-citrate lyase in association with the reduced gene expression of sterol response elementbinding factor (SREBF)-1 and SREBF-2, key transcription factors for the gene expression of lipogenic enzymes $^{90)}$ (Fig. 6). In accordance with the results for these changes in hepatic gene expression of lipogenic enzymes, the plasma levels of triglycerides and cholesterol of mice given a diet containing the EGCG-free fraction were significantly reduced ${ }^{90)}$ (Table 1). The plasma glucose levels were not altered significantly, but tended to be reduced (Table 1). Thus, green tea contains some component(s) other than catechins which may have anti-obesity and antiatherosclerotic effects.

Anti-atherosclerotic effects of catechins have often been reported. For example, Muramatsu et $a l^{91)}$ found that tea catechins decreased plasma total cholesterol, cholesterol ester, and total cholesterol-HDL-cholesterol (VIDL-+LDL-cholesterol) levels and lowered the atherogenic index (VLDL-+LDLcholesterol/HDL-cholesterol), indicating that they exert a hypocholesterolemic effect, in cholesterol-fed rats. Catechins have been shown to prevent vascular smooth muscle cell invasion by inhibiting MT1-MMP activity and MMP-2 expression. ${ }^{92)}$ The ability of green tea to prevent cell invasion and matrix degradation might contribute to its protective effect on atherosclerosis and cancer.

A recent report has revealed a potential role for green tea in the prevention of cardiovascular disease. ${ }^{93)}$ A population-based, prospective cohort study initiated in 1994 among 40,530 Japanese adults aged 40 to 79 years without a history of stroke, coronary heart disease, or cancer at baseline indicated that over 11 years of follow-up, 4209 participants died, and over 7 years of follow-up, 892 participants died of cardiovascular disease and 1134 participants died of cancer. The results of statistical analyses indicated that green tea consumption was inversely associated with mortality due to all causes and due to cardiovascular disease.

\section{Other effects}

It was shown that EGCG suppressed experimental autoimmune encephalomyelitis induced by proteolipid protein $139-151$ in mice. ${ }^{94)}$ EGCG reduced clinical severity when given at initiation or after the 


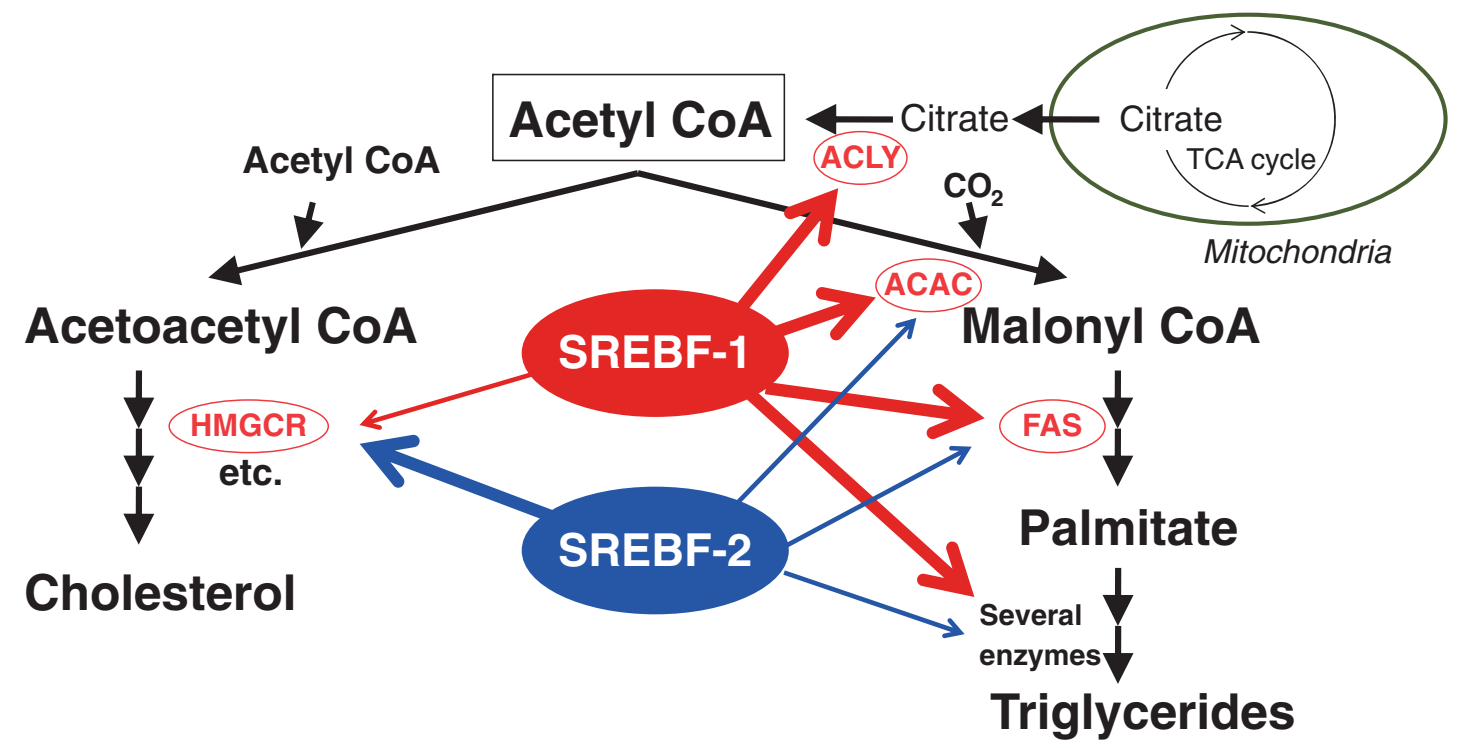

Fig. 6. Central roles of sterol response element-binding factors (SREBFs) in lipogenesis. Colored thick and thin lines represent the major and minor sites of action for SREBF-1 and SREBF-2, respectively. ACLY, ATP-citrate lyase; ACAC, acetyl CoA carboxylase; FAS, fatty acid synthase; HMGCR, 4-hydroxymethylglutaryl CoA reductase; TCA, citric acid cycle.

Table 1. Effects of a diet containing an EGCG-free green tea fraction on plasma levels of glucose, triglycerides and cholesterol

\begin{tabular}{lccc}
\hline & $0 \%$ & $0.2 \%$ & $0.5 \%$ \\
\hline Glucose $(\mathrm{mg} / \mathrm{dl})$ & $165.2 \pm 9.1$ & $152.5 \pm 1.3$ & $144.6 \pm 6.9$ \\
Triglycerides $(\mathrm{mg} / \mathrm{dl})$ & $164.7 \pm 20.1$ & $128.94 \pm 10.4$ & $101.13 \pm 10.2^{*}$ \\
Cholesterol $(\mathrm{mg} / \mathrm{dl})$ & $107.8 \pm 3.7$ & $94.24 \pm 2.4^{*}$ & $92.18 \pm 2.7^{*}$ \\
\hline The plasma levels were determined for the mice $(\mathrm{n}=5)$ given a \\
diet containing $0.2 \%$ or $0.5 \%$ of an EGCG-free fraction derived \\
from green tea and compared with those of control mice given \\
a normal diet. ${ }^{87)}$ The results are expressed as the mean \pm \\
standard error of 3 determinations. ${ }^{*}$ Significantly different \\
from the control at $p<0.05$.
\end{tabular}

onset of encephalomyelitis by both limiting brain inflammation and reducing neuronal damage. Mice given EGCG orally showed abrogated proliferation and TNF- $\alpha$ production in encephalitogenic T cells. Proposed models for signal transduction pathways modified by EGCG include: EGCG is capable of inhibiting both catalytic activities of the proteasome, including the activation of NF- $\kappa \mathrm{B}$, and the amount of ROS produced (Fig. 4). In lymphocytes, this leads to decreased proliferation and production of $\mathrm{TNF}-\alpha$, while in neurons, it results in less damage. Additionally, the antioxidative effects of EGCG on neurons might involve the NF- $\kappa \mathrm{B}$ pathway as well, since an oxidative stress can induce production of NF- $\kappa \mathrm{B}$, which regulates the expression of a variety of factors contributing to cell proliferation, inflammation, and neuronal damage. Thus, a natural green tea constituent may open up a new therapeutic avenue for young disabled adults with inflammatory brain disease by combining, on the one hand, anti-inflammatory and, on the other, neuroprotective capacities.

Rezai-Zadeh et al..$^{95)}$ showed that EGCG modulated cleavage of the amyloid precursor protein and reduced cerebral amyloidosis in Alzheimer transgenic mice. Daily consumption of green tea catechins may delay memory regression in aged mice as shown by Unno et al. ${ }^{96)}$ Thus, green tea catechins are expected to have beneficial effects on brain functions. A recent epidemiological study has indicated that consumption of green tea is associated with a lower prevalence of cognitive impairment in humans. ${ }^{97)}$

Methylated EGCG ((-)-epigallocatechin 3-O(3-O-methyl) gallate) was demonstrated to inhibit degranulation from cells that had been stimulated with the calcium ionophore A23187 in the human basophilic cell line KU812. ${ }^{8), 98)}$ This result indicates that methylation of EGCG may be an effective means of modifying catechins to inhibit degranulation from human basophils and prevent clinical symptoms. In addition, EGCG and methylated EGCG were shown to have the ability to downregulate Fc epsilon RI expression, and this suppressive effect may be due to a reduction of $\mathrm{F} c \varepsilon \mathrm{RI} \alpha$ and $\gamma$ mRNA levels. ${ }^{8), 99), 100)}$ However, caution is 
needed for human application since EGCG has been identified as a causative agent in patients with green tea-induced asthma. ${ }^{101)}$

Theanine and $\gamma$-aminobutyric acid are also characteristic components of green tea. Using an in vivo brain microdialysis method, Yamada et al. ${ }^{102)}$ demonstrated that theanine affects the release of neurotransmitters in the rat striatum. Recently, theanine was reported to enhance the synthesis of nerve growth factor and neurotransmitters during a nerve maturing period and promote maturation of the central nervous system. ${ }^{103)}$ Electroencephalograms of volunteers who received $200 \mathrm{mg}$ of theanine revealed the generation of $\alpha$ wave activity suggesting relaxation. $\gamma$-Aminobutyric acid is perhaps the most important inhibitory neurotransmitter in the brain, and its intake will affect brain functions. Thus, effects on brain function are a very important target for future investigations of green tea.

\section{Conclusion}

Modern scientific techniques have given the basis for the health-promoting effects of green tea, which have been recognized from ancient times. Many of the action mechanisms of green tea and its constituent EGCG are now known. For example, EGCG binds several enzyme proteins to inhibit their activities, induces oxidative stress in cells, and initiate signal transduction by binding to cell surface proteins. Our recent studies revealed that green tea and EGCG may cause changes in the mRNA levels of gluconeogenic and lipogenic enzymes by changing the expression levels of the respective transcription factors, HNFs and SREBFs. However, these findings pose new questions on the mechanism of how green tea and its constituents can induce changes in the level of the transcription factors. In addition, we demonstrated that an EGCG-free fraction of green tea had certain health-promoting effects, but the active entity remains to be determined. Although these and other questions await future investigations, epidemiological studies seem to indicate that ingestion of green tea contributes to human healthpromotion. Future clinical intervention studies will provide more convincing evidence for effects of green tea.

\section{References}

1) Kuroda, Y. and Hara, Y. (1999) Antimutagenic and anticarcinogenic activity of tea polyphenols. Mutat. Res. 436, 69-97.
2) Sun, C.L., Yuan, J.M., Lee, M.J., Yang, C.S., Gao, Y.T., Ross, R.K., Yang, C.S. and Yu, M.C. (2002) Urinary tea polyphenols in relation to gastric and esophageal cancers: prospective study of men in Shanghai, China. Carcinogenesis 23, 1497-1503.

3) Fujiki, H. and Suganuma, M. (2002) Green tea and cancer prevention. Proc. Jpn. Acad., Ser. B, Phys. Biol. Sci. 78, 263-270.

4) Koo, M.W. and Cho, C.H. (2004) Pharmacological effects of green tea on the gastrointestinal system. Eur. J. Pharmacol. 500, 177-185.

5) Cabrera, C., Artacho, R. and Giménez, R. (2006) Beneficial effects of green tea-a review. J. Am. Coll. Nutr. 25, 79-99.

6) Bun, S.S., Bun, H., Guédon, D., Rosier, C. and Ollivier, E. (2006) Effect of green tea extracts on liver functions in Wistar rats. Food Chem. Toxicol. 44, 1108-1113.

7) Wolfram, S. (2007) Effects of green tea and EGCG on cardiovascular and metabolic health. J. Am. Coll. Nutr. 26, 373S-388S.

8) Tachibana, H. (2011) Green tea polyphenol sensing. Proc. Jpn. Acad., Ser. B, Phys. Biol. Sci. 87, 6680.

9) Shimizu, M., Adachi, S., Masuda, M., Kozawa, O. and Moriwaki, H. (2011) Cancer chemoprevention with green tea catechins by targeting receptor tyrosine kinases. Mol. Nutr. Food Res. 55, 832843.

10) Suganuma, M., Saha, A. and Fujiki, H. (2011) New cancer treatment strategy using combination of green tea catechins and anticancer drugs. Cancer Sci. 102, 317-323.

11) Pan, M.H., Chiou, Y.S., Wang, Y.J., Ho, C.T. and Lin, J.K. (2011) Multistage carcinogenesis process as molecular targets in cancer chemoprevention by epicatechin-3-gallate. Food Funct. 2, 101-110.

12) Yang, C.S. and Wang, H. (2011) Mechanistic issues concerning cancer prevention by tea catechins. Mol. Nutr. Food Res. 55, 819-831.

13) Isemura, M., Suzuki, Y., Satoh, K., Narumi, K. and Motomiya, M. (1993) Effects of catechins on the mouse lung carcinoma cell adhesion to the endothelial cells. Cell Biol. Int. 17, 59-64.

14) Ogata, K., Mukae, N., Suzuki, Y., Satoh, K., Narumi, K., Nukiwa, T., Ogata, K. and Isemura, M. (1995) Effects of catechins on the mouse tumor cell adhesion to fibronectin. Planta Med. 61, 472474.

15) Suzuki, Y. and Isemura, M. (2001) Inhibitory effect of epigallocatechin gallate on adhesion of murine melanoma cells to laminin. Cancer Lett. 173, 1520.

16) Yamaguchi, Y., Isemura, M., Yosizawa, Z., Kurosawa, K., Yoshinaga, K., Sato, A. and Suzuki, M. (1985) Changes in the distribution of fibronectin in the placenta during normal human pregnancy. Am. J. Obstet. Gynecol. 152, 715718.

17) Kurosawa, K., Isemura, M., Yamaguchi, Y. Yosizawa, Z., Furuyama, T., Yoshinaga, K. and Ishii, T. (1985) Changes in distribution of 
connective tissue components of human placentae with maturation. Tohoku J. Exp. Med. 147, 261265.

18) Sazuka, M., Murakami, S., Isemura, M., Satoh, K. and Nukiwa, T. (1995) Inhibitory effects of green tea infusion on in vitro invasion and in vivo metastasis of mouse lung carcinoma cells. Cancer Lett. 98, 27-31.

19) Taniguchi, S., Fujiki, H., Kobayashi, H., Go, H., Miyado, K., Sadano, H. and Shimokawa, R. (1992) Effect of (-)-epigallocatechin gallate, the main constituent of green tea, on lung metastasis with mouse B16 melanoma cell lines. Cancer Lett. 6, 51-54.

20) Sazuka, M., Imazawa, H., Shoji, Y., Mita, T., Hara, Y. and Isemura, M. (1997) Inhibition of collagenases from mouse lung carcinoma cells by green tea catechins and black tea theaflavins. Biosci. Biotechnol. Biochem. 61, 1504-1506.

21) Maeda-Yamamoto, M., Kawahara, H., Tahara, N., Tsuji, K., Hara, Y. and Isemura, M. (1999) Effects of tea polyphenols on the invasion and matrix metalloproteinases activities of human fibrosarcoma HT1080 cells. J. Agric. Food Chem. 47, 23502354 .

22) Isemura, M., Saeki, K., Kimura, T., Hayakawa, S., Minami, T. and Sazuka, M. (2000) Tea catechins and related polyphenols as anti-cancer agents. Biofactors 13, 81-85.

23) Sazuka, M., Itoi, T., Suzuki, Y., Odani, S., Koide, T. and Isemura, M. (1996) Evidence for the interaction between (-)-epigallocatechin gallate and human plasma proteins fibronectin, fibrinogen, and histidine-rich glycoprotein. Biosci. Biotechnol. Biochem. 60, 1317-1319.

24) Sazuka, M., Isemura, M. and Isemura, S. (1998) Interaction between the carboxyl-terminal heparin-binding domain of fibronectin and (-)epigallocatechin gallate. Biosci. Biotechnol. Biochem. 62, 1031-1032.

25) Isemura, M., Saeki, K., Minami, T., Hayakawa, S., Kimura, T., Shoji, Y., Isemura, M. and Sazuka, M. (1999) Inhibition of matrix metalloproteinases by tea catechins and related polyphenols. Ann. N. Y. Acad. Sci. 878, 629-631.

26) Maeda-Yamamoto, M., Suzuki, N., Sawai, Y., Miyase, T., Sano, M., Hashimoto-Ohta, A. and Isemura, M. (2003) Association of suppression of extracellular signal-regulated kinase phosphorylation by epigallocatechin gallate with the reduction of matrix metalloproteinase activities in human fibrosarcoma HT1080 cells. J. Agric. Food Chem. $\mathbf{5 1}, \mathbf{1 8 5 8 - 1 8 6 3 .}$

27) Gunji, H., Kharbanda, S. and Kufe, D. (1993) Induction of internucleosomal DNA fragmentation in human myeloid leukemia cells by $1-\beta$ D-arabinofuranosylcytosine. Cancer Res. 51, 741743.

28) Skladanowski, A. and Konopa, J. (1991) Adriamycin and daunomycin induce programmed cell death (apoptosis) in tumour cells. Biochem. Pharmacol. 46, 375-382.
29) Yang, G.Y., Liao, J., Li, C., Chung, J., Yurkow, E.J., Ho, C.T. and Yang, C.S. (2000) Effect of black and green tea polyphenols on c-jun phosphorylation and $\mathrm{H}_{2} \mathrm{O}_{2}$ production in transformed and non-transformed human bronchial cell lines: possible mechanisms of cell growth inhibition and apoptosis induction. Carcinogenesis $\mathbf{2 1}$, 2035-2039.

30) Ahmad, N., Cheng, P. and Mukhtar, H. (2000) Cell cycle dysregulation by green tea polyphenol epigallocatechin-3-gallate. Biochem. Biophys. Res. Commun. 275, 328-334.

31) Fujiki, H., Suganuma, M., Okabe, S., Sueoka, N., Komori, A., Sueoka, E., Kozu, T., Tada, Y., Suga, K., Imai, K. and Nakachi, K. (1998) Cancer inhibition by green tea. Mutat. Res. 402, 307310.

32) Saeki, K., Kobayashi, N., Inazawa, Y., Zhang, H., Nishitoh, H., Ichijo, H., Saeki, K., Isemura, M. and Yuo, A. (2002) Oxidation-triggered c-Jun Nterminal kinase (JNK) and p38 mitogen-activated protein (MAP) kinase pathways for apoptosis in human leukaemic cells stimulated by epigallocatechin-3-gallate (EGCG): a distinct pathway from those of chemically induced and receptormediated apoptosis. Biochem. J. 368, 705-720.

33) Hibasami, H., Achiwa, Y., Fujikawa, T. and Komiya, T. (1996) Induction of programmed cell death (apoptosis) in human lymphoid leukemia cells by catechin compounds. Anticancer Res. 16, 1943-1946.

34) Saeki, K., Sano, M., Miyase, T., Nakamura, Y., Hara, Y., Aoyagi, Y. and Isemura, M. (1999) Apoptosis-inducing activity of polyphenol compounds derived from tea catechins in human histiolytic lymphoma U937 cells. Biosci. Biotechnol. Biochem. 63, 585-587.

35) Saeki, K., Hayakawa, S., Isemura, M. and Miyase, T. (2000) Importance of a pyrogallol-type structure in catechin compounds for apoptosis-inducing activity. Phytochemistry 53, 391-394.

36) Ohishi, T., Kishimoto, Y., Miura, N., Shiota, G., Kohri, T., Hara, Y., Hasegawa, J. and Isemura, M. (2002) Synergistic effects of (-)-epigallocatechin gallate with sulindac against colon carcinogenesis of rats treated with azoxymethane. Cancer Lett. 177, 49-56.

37) Gupta, S., Hastak, K., Ahmad, N., Lewin, J.S. and Mukhtar, H. (2001) Inhibition of prostate carcinogenesis in TRAMP mice by oral infusion of green tea polyphenols. Proc. Natl. Acad. Sci. U.S.A. 98, 10350-10355.

38) Hayakawa, S., Saeki, K., Sazuka, M., Suzuki, Y., Shoji, Y., Ohta, T., Kaji, K., Yuo, A. and Isemura, M. (2001) Apoptosis induction by epigallocatechin gallate involves its binding to Fas. Biochem. Biophys. Res. Commun. 285, 1102-1106.

39) Ermakova, S., Choi, B.Y., Choi, H.S., Kang, B.S., Bode, A.M. and Dong, Z. (2005) The intermediate filament protein vimentin is a new target for epigallocatechin gallate. J. Biol. Chem. 280, 
16882-16890.

40) Suzuki, Y., Suzuki, T., Minami, T. and Isemura, M. (2006) Involvement of impaired interaction with $\beta 1$ integrin in epigallocatechin gallate-mediated inhibition of fibrosarcoma HT-1080 cell adhesion to fibronectin. J. Health Sci. 52, 103-109.

41) Ermakova, S.P., Kang, B.S., Choi, B.Y., Choi, H.S., Schuster, T.F., Ma, W.Y., Bode, A.M. and Dong, Z. (2006) (-)-Epigallocatechin gallate overcomes resistance to etoposide-induced cell death by targeting the molecular chaperone glucose-regulated protein 78. Cancer Res. 66, 9260-9269.

42) Li, M., He, Z., Ermakova, S., Zheng, D., Tang, F., Cho, Y.Y., Zhu, F., Ma, W.Y., Sham, Y., Rogozin, E.A., Bode, A.M., Cao, Y. and Dong, Z. (2007) Direct inhibition of insulin-like growth factor-I receptor kinase activity by (-)-epigallocatechin-3gallate regulates cell transformation. Cancer Epidemiol. Biomarkers Prev. 16, 598-605.

43) He, Z., Tang, F., Ermakova, S., Li, M., Zhao, Q., Cho, Y.Y., Ma, W.Y., Choi, H.S., Bode, A.M., Yang, C.S. and Dong, Z. (2008) Fyn is a novel target of (-)-epigallocatechin gallate in the inhibition of JB6 Cl41 cell transformation. Mol. Carcinog. 47, 172-183.

44) Shim, J.H., Choi, H.S., Pugliese, A., Lee, S.Y., Chae, J.I., Choi, B.Y., Bode, A.M. and Dong, Z. (2008) (-)-Epigallocatechin gallate regulates CD3-mediated $\mathrm{T}$ cell receptor signaling in leukemia through the inhibition of ZAP-70 kinase. J. Biol. Chem. 283, 28370-28379.

45) Tanaka, T., Ishii, T., Mizuno, D., Mori, T., Yamaji, R., Nakamura, Y., Kumazawa, S., Nakayama, T. and Akagawa, M. (2011) (-)-Epigallocatechin-3gallate suppresses growth of AZ521 human gastric cancer cells by targeting the DEAD-box RNA helicase p68. Free Radic. Biol. Med. 50, 13241335.

46) Chen, Z.P., Schell, J.B., Ho, C.T. and Chen, K.Y. (1998) Green tea epigallocatechin gallate shows a pronounced growth inhibitory effect on cancerous cells but not on their normal counterparts. Cancer Lett. 129, 173-179.

47) Ahmad, N., Gupta, S. and Mukhtar, H. (2000) Green tea polyphenol epigallocatechin-3-gallate differentially modulates nuclear factor $\kappa \mathrm{B}$ in cancer cells versus normal cells. Arch. Biochem. Biophys. 376, 338-346.

48) Ichikawa, H., Kunii, M. and Isemura, M. (2004) Mechanism of apoptosis induction selective for cancer cells by EGCG. 2004 International Conference on O-Cha (tea) Culture and Science. Abstracts, p. 99.

49) Okada, N., Tanabe, H., Tazoe, H., Ishigami, Y., Fukutomi, R., Yasui, K. and Isemura, M. (2009) Differentiation-associated alteration in sensitivity to apoptosis induced by (-)-epigallocatechin-3-Ogallate in HL-60 cells. Biomed. Res. 30, 201-206.

50) Hayakawa, S., Kimura, T., Saeki, K., Koyama, Y., Aoyagi, Y., Noro, T., Nakamura, Y. and Isemura, M. (2001) Apoptosis-inducing activity of high molecular weight fractions of tea extracts. Biosci.
Biotechnol. Biochem. 65, 459-462.

51) Ohata, M., Koyama, Y., Suzuki, T., Hayakawa, S., Saeki, K., Nakamura, Y. and Isemura, M. (2005) Effects of tea constituents on cell cycle progression of human leukemia U937 cells. Biomed. Res. 26, $1-7$.

52) Oguni, I., Nasu, K., Kanaya, S., Ota, Y., Yamamoto, S. and Komura, T. (1989) Epidemiological and experimentals studies on the antitumor activity by green tea extracts. Japan J. Nutr. 47, 93-102.

53) Tsubono, Y., Nishino, Y., Komatsu, S., Hsieh, C.C., Kanemura, S., Tsuji, I., Nakatsuka, H., Fukao, A., Satoh, H. and Hisamichi, S. (2001) Green tea and the risk of gastric cancer in Japan. N. Engl. J. Med. 344, 632-636.

54) Hoshiyama, Y., Kawaguchi, T., Miura, Y., Mizoue, T., Tokui, N., Yatsuya, H., Sakata, K., Kondo, T., Kikuchi, S., Toyoshima, H., Hayakawa, N., Tamakoshi, A., Ohno, Y. and Yoshimura, T. (2004) A nested case-control study of stomach cancer in relation to green tea consumption in Japan. Br. J. Cancer 90, 135-138.

55) Sasazuki, S., Inoue, M., Hanaoka, T., Yamamoto, S., Sobue, T. and Tsugane, S. (2004) Green tea consumption and subsequent risk of gastric cancer by subsite: the JPHC Study. Cancer Causes Control 15, 483-491.

56) Kang, H., Rha, S.Y., Oh, K.W. and Nam, C.M. (2010) Green tea consumption and stomach cancer risk: a meta-analysis. Epidemiol. Health 32, e2010001.

57) Bettuzzi, S., Brausi, M., Rizzi, F., Castagnetti, G., Peracchia, G. and Corti, A. (2006) Chemoprevention of human prostate cancer by oral administration of green tea catechins in volunteers with high-grade prostate intraepithelial neoplasia: a preliminary report from a one-year proof-ofprinciple study. Cancer Res. 66, 1234-1240.

58) Gross, G., Meyer, K.G., Pres, H., Thielert, C., Tawfik, H. and Mescheder, A. (2007) A randomized, double-blind, four-arm parallel-group, placebo-controlled Phase II/III study to investigate the clinical efficacy of two galenic formulations of Polyphenon E in the treatment of external genital warts. J. Eur. Acad. Dermatol. Venereol. 21, 1404-1412.

59) Tzellos, T.G., Sardeli, C., Lallas, A., Papazisis, G., Chourdakis, M. and Kouvelas, D. (2011) Efficacy, safety and tolerability of green tea catechins in the treatment of external anogenital warts: a systematic review and meta-analysis. J. Eur. Acad. Dermatol. Venereol. 25, 345-353.

60) Keppler, D., Lesch, R., Reutter, W. and Decker, K. (1968) Experimental hepatitis induced by Dgalactosamine. Exp. Mol. Pathol. 9, 279-290.

61) Sugiyama, K., He, P., Wada, S., Tamaki, F. and Saeki, S. (1998) Green tea suppresses D-galactosamine-induced liver injury in rats. Biosci. Biotechnol. Biochem. 62, 609-611.

62) Wada, S., He, P., Watanabe, N., Sakata, K. and Sugiyama, K. (1999) Suppression of D-galactos- 
amine-induced rat liver injury by glycosidic flavonoids-rich fraction from green tea. Biosci. Biotechnol. Biochem. 63, 570-572.

63) Abe, K., Ijiri, M., Suzuki, T., Taguchi, K., Koyama, Y. and Isemura, M. (2005) Green tea with a high catechin content suppresses inflammatory cytokine expression in the galactosamine-injured rat liver. Biomed. Res. 26, 187-192.

64) Itokazu, Y., Segawa, Y., Inoue, N. and Omata, T. (1999) D-galactosamine-induced mouse hepatic apoptosis: possible involvement with tumor necrosis factor, but not with caspase-3 activity. Biol. Pharm. Bull. 22, 1127-1130.

65) Okabe, S., Ochiai, Y., Aida, M., Park, K., Kim, S.J., Nomura, T., Suganuma, M. and Fujiki, H. (1999) Mechanistic aspects of green tea as a cancer preventive: effect of components on human stomach cancer cell lines. Jpn. J. Cancer Res. 90, 733-739.

66) Giakoustidis, D.E., Giakoustidis, A.E., Iliadis, S., Koliakou, K., Antoniadis, N., Kontos, N., Papanikolaou, V., Papageorgiou, G., Kaldrimidou, E. and Takoudas, D. (2010) Attenuation of liver ischemia/reperfusion induced apoptosis by epigallocatechin-3-gallate via downregulation of NF- $\kappa \mathrm{B}$ and c-Jun expression. J. Surg. Res. 159, 720-728.

67) Moller, D.E. (2000) Potential role of TNF- $\alpha$ in the pathogenesis of insulin resistance and type 2 diabetes. Trends Endocrinol. Metab. 11, 212-217.

68) Abe, K., Suzuki, T., Ijiri, M., Koyama, Y., Isemura, M. and Kinae, N. (2007) The anti-fibrotic effect of green tea with a high catechin content in the galactosamine-injured rat liver. Biomed. Res. 28, 43-48.

69) Sameshima, Y., Ishida, Y., Ono, Y., Hujita, M. and Kuriki, Y. (2008) Green tea powder enhances the safety and efficacy of interferon $\alpha$-2b plus ribavirin combination therapy in chronic hepatitis $\mathrm{C}$ patients with a very high genotype $1 \mathrm{HCV}$ load. In Beneficial Health Effects of Green Tea (ed. Isemura, M.). Research Signpost, Trivandrum, India, pp. 113-119.

70) Bonkovsky, H.L. (2006) Hepatotoxicity associated with supplements containing Chinese green tea (Camellia sinensis). Ann. Intern. Med. 144, 6871.

71) Bun, S.S., Bun, H., Guédon, D., Rosier, C. and Ollivier, E. (2006) Effect of green tea extracts on liver functions in Wistar rats. Food Chem. Toxicol. 44, 1108-1113.

72) Anderson, R.A. and Polansky, M.M. (2002) Tea enhances insulin activity. J. Agric. Food Chem. 50, $7182-7186$.

73) Tsuneki, H., Ishizuka, M., Terasawa, M., Wu, J.B., Sasaoka, T. and Kimura, I. (2004) Effect of green tea on blood glucose levels and serum proteomic patterns in diabetic $(\mathrm{db} / \mathrm{db})$ mice and on glucose metabolism in healthy humans. BMC Pharmacol. 4, 18.

74) Wu, L.Y., Juan, C.C., Ho, L.T., Hsu, Y.P. and Hwang, L.S. (2004) Effect of green tea supple- mentation on insulin sensitivity in SpragueDawley rats. J. Agric. Food Chem. 52, 643-648.

75) Sayama, K., Lin, S., Zheng, G. and Oguni, I. (2000) Effects of green tea on growth, food utilization and lipid metabolism in mice. In Vivo 14, 481484.

76) Waltner-Law, M.E., Wang, X.L., Law, B.K., Hall, R.K., Nawano, M. and Granner, D.K. (2002) Epigallocatechin gallate, a constituent of green tea, represses hepatic glucose production. J. Biol. Chem. 277, 34933-34940.

77) Koyama, Y., Abe, K., Sano, Y., Ishizaki, Y., Njelekela, M., Shoji, Y., Hara, Y. and Isemura, M. (2004) Effects of green tea on gene expression of hepatic gluconeogenic enzymes in vivo. Planta Med. 70, 1100-1102.

78) Wolfram, S., Raederstorff, D., Preller, M., Wang, Y., Teixeira, S.R., Riegger, C. and Weber, P. (2006) Epigallocatechin gallate supplementation alleviates diabetes in rodents. J. Nutr. 136, 25122518.

79) Yasui, K., Tanabe, H., Okada, N., Fukutomi, R., Ishigami, Y. and Isemura, M. (2010) Effects of catechin-rich green tea on gene expression of gluconeogenic enzymes in rat hepatoma H4IIE cells. Biomed. Res. 31, 183-189.

80) Xie, X., Liao, H., Dang, H., Pang, W., Guan, Y., Wang, X., Shyy, J.Y., Zhu, Y. and Sladek, F.M. (2009) Down-regulation of hepatic HNF4 $\alpha$ gene expression during hyperinsulinemia via SREBPs. Mol. Endocrinol. 23, 434-443.

81) Yasui, K., Tanabe, H., Miyoshi, N., Suzuki, T., Goto, G., Taguchi, K., Ishigami, Y., Paeng, N., Fukutomi, R., Imai, S. and Isemura, M. (2011) Effects of (-)-epigallocatechin-3-O-gallate on expression of gluconeogenesis-related genes in the mouse duodenum. Biomed. Res. 32, 313-320.

82) Yasui, K., Miyoshi, N., Tababe, H., Ishigami, Y., Fukutomi, R., Imai, S. and Isemura, M. (2011) Effects of oolong tea on gene expression of gluconeogenic enzymes in the mouse liver and in rat hepatoma H4IIE cells. J. Med. Food 14, 930938.

83) Yasui, K., Miyoshi, N., Tanabe, H., Ishigami, Y., Fukutomi, R., Imai, S. and Isemura, M. (2011) Effects of a catechin-free fraction derived from green tea on gene expression of gluconeogenic enzymes in rat hepatoma H4IIE cells and in the mouse liver. Biomed. Res. 32, 119-125.

84) Iso, H., Date, C., Wakai, K., Fukui, M. and Tamakoshi, A.; JACC Study Group (2006) The relationship between green tea and total caffeine intake and risk for self-reported type 2 diabetes among Japanese adults. Ann. Intern. Med. 144, 554-562.

85) Panagiotakos, D.B., Lionis, C., Zeimbekis, A. Gelastopoulou, K., Papairakleous, N., Das, U.N. and Polychronopoulos, E. (2009) Long-term tea intake is associated with reduced prevalence of (type 2) diabetes mellitus among elderly people from Mediterranean islands: MEDIS epidemiological study. Yonsei Med. J. 50, 31-38. 
86) Chacko, S.M., Thambi, P.T., Kuttan, R. and Nishigaki, I. (2010) Beneficial effects of green tea: a literature review. Chin. Med. 5, 13.

87) Thavanesan, N. (2011) The putative effects of green tea on body fat: an evaluation of the evidence and a review of the potential mechanisms. Br. J. Nutr. 106, 1297-1309.

88) Rains, T.M., Agarwal, S. and Maki, K.C. (2011) Antiobesity effects of green tea catechins: a mechanistic review. J. Nutr. Biochem. 22, 1-7.

89) Lin, J.K. and Lin-Shiau, S.Y. (2006) Mechanisms of hypolipidemic and anti-obesity effects of tea and tea polyphenols. Mol. Nutr. Food Res. 50, 211217.

90) Yasui, K., Paeng, N., Miyoshi, N., Suzuki, T., Taguchi, K., Ishigami, Y., Fukutomi, R., Imai, S., Isemura, M. and Nakayama, T. (2012) Effects of a catechin-free fraction derived from green tea on gene expression of enzymes related to lipid metabolism in the mouse liver. Biomed. Res. 33, 9-13.

91) Muramatsu, K., Fukuyo, M. and Hara, Y. (1986) Effect of green tea catechins on plasma cholesterol level in cholesterol-fed rats. J. Nutr. Sci. Vitaminol. (Tokyo) 32, 613-622.

92) El Bedoui, J., Oak, M.H., Anglard, P. and SchiniKerth, V.B. (2005) Catechins prevent vascular smooth muscle cell invasion by inhibiting MT1MMP activity and MMP-2 expression. Cardiovasc. Res. 67, 317-325.

93) Kuriyama, S., Shimazu, T., Ohmori, K., Kikuchi, N., Nakaya, N., Nishino, Y., Tsubono, Y. and Tsuji, I. (2006) Green tea consumption and mortality due to cardiovascular disease, cancer, and all causes in Japan: the Ohsaki study. JAMA 296, 1255-1265.

94) Aktas, O., Prozorovski, T., Smorodchenko, A., Savaskan, N.E., Lauster, R., Kloetzel, P.M., Infante-Duarte, C., Brocke, S. and Zipp, F. (2004) Green tea epigallocatechin-3-gallate mediates $\mathrm{T}$ cellular $\mathrm{NF}-\kappa \mathrm{B}$ inhibition and exerts neuroprotection in autoimmune encephalomyelitis. J. Immunol. 173, 5794-5800.

95) Rezai-Zadeh, K., Shytle, D., Sun, N., Mori, T., Hou, H., Jeanniton, D., Ehrhart, J., Townsend, K., Zeng, J., Morgan, D., Hardy, J., Town, T. and Tan, J. (2005) Green tea epigallocatechin-3gallate (EGCG) modulates amyloid precursor protein cleavage and reduces cerebral amyloidosis in Alzheimer transgenic mice. J. Neurosci. 25, 8807-8814.

96) Unno, K., Takabayashi, F., Yoshida, H., Choba, D., Fukutomi, R., Kikunaga, N., Kishido, T., Oku, N. and Hoshino, M. (2007) Daily consumption of green tea catechin delays memory regression in aged mice. Biogerontology 8, 89-95.

97) Kuriyama, S., Hozawa, A., Ohmori, K., Shimazu, T., Matsui, T., Ebihara, S., Awata, S., Nagatomi, R., Arai, H. and Tsuji, I. (2006) Green tea consumption and cognitive function: a cross-sectional study from the Tsurugaya Project 1. Am. J. Clin. Nutr. 83, 355-361.

98) Tachibana, H., Sunada, Y., Miyase, T., Sano, M., Maeda-Yamamoto, M. and Yamada, K. (2000) Identification of a methylated tea catechin as an inhibitor of degranulation in human basophilic KU812 cells. Biosci. Biotechnol. Biochem. 64, 452-454.

99) Fujimura, Y., Tachibana, H. and Yamada, K. (2001) A tea catechin suppresses the expression of the high-affinity $\mathrm{IgE}$ receptor $\mathrm{F} c \varepsilon \mathrm{RI}$ in human basophilic KU812 cells. J. Agric. Food Chem. 49, 2527-2531.

100) Fujimura, Y., Tachibana, H., Maeda-Yamamoto, M., Miyase, T., Sano, M. and Yamada, K. (2002) Antiallergic tea catechin, (-)-epigallocatechin-3$O$-(3-O-methyl)-gallate, suppresses Fc $\varepsilon \mathrm{RI}$ expression in human basophilic KU812 cells. J. Agric. Food Chem. 50, 5729-5734.

101) Shirai, T., Hayakawa, H., Akiyama, J., Iwata, M., Chida, K., Nakamura, H., Taniguchi, M. and Reshad, K. (2003) Food allergy to green tea. J. Allergy Clin. Immunol. 112, 805-806.

102) Yamada, T., Terashima, T., Okubo, T., Juneja, L.R. and Yokogoshi, H. (2005) Effects of theanine, $\gamma$-glutamylethylamide, on neurotransmitter release and its relationship with glutamic acid neurotransmission. Nutr. Neurosci. 8, 219-226.

103) Yamada, T., Terashima, T., Wada, K., Ueda, S., Ito, M., Okubo, T., Juneja, L.R. and Yokogoshi, H. (2007) Theanine, $\gamma$-glutamylethylamide, increases neurotransmission concentrations and neurotrophin mRNA levels in the brain during lactation. Life Sci. 81, 1247-1255.

(Received Oct. 30, 2011; accepted Jan. 6, 2012) 


\section{Profile}

Mamoru Isemura was born in 1941 in Kobe and graduated from Osaka University Faculty of Science in 1963. He studied organic biological chemistry under the direction of Prof. Y. Matsushima and received a Ph.D. in 1968 from Osaka University. He went to the USA to join Prof. Karl Schmid in Boston and initiated the studies of glycoproteins. He was appointed as an associate professor at Niigata University School of Medicine (Prof. Tokuji Ikenaka) in 1971, and moved to Tohoku University School of Medicine (Prof. Zensaku Yosizawa) in 1980. He was appointed as a professor at Shizuoka Women's University and then at the University of Shizuoka in 1985, where he started investigations on bioactive plant extracts including green tea. He was dean of School of Food and Nutritional Sciences, dean of Graduate School of Nutritional and

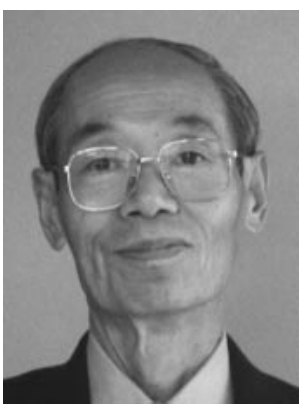
Environmental Sciences, and director of the University Library. He retired from the University of Shizuoka in 2006 and was a guest professor of the laboratory funded by the Nisshin Seifun Group in the University of Shizuoka until 2010. He is professor emeritus of the University of Shizuoka and an honorary member of the Japanese Society of Catechinology. 